\title{
CONTROLE DE PLANTAS DANINHAS NA CULTURA DE SOJA RESISTENTE AO GLYPHOSATE $\left({ }^{\mathbf{1}}\right)$
}

\author{
NÚBIA MARIA CORREIA $\left({ }^{2 *}\right)$; JULIO CEZAR DURIGAN $\left({ }^{2}\right)$
}

\begin{abstract}
RESUMO
O objetivo da pesquisa foi avaliar o controle de plantas daninhas em área cultivada com soja resistente ao herbicida glyphosate, sem a utilização de práticas complementares de manejo de plantas daninhas. Foram desenvolvidos experimentos, em condições de campo, nos anos agrícolas 2005/2006 e 2006/2007 em Jaboticabal (SP). Foram avaliadas duas cultivares de soja resistentes ao glyphosate (CD 214 RR e M-SOY 8008 RR), oito tratamentos de herbicidas (glyphosate, em aplicação única, nas doses de 0,48; 0,72; 0,96 e $1,20 \mathrm{~kg} \mathrm{ha}^{-1}$ de equivalente ácido, associadas ou não a aplicação sequencial na dose de $0,48 \mathrm{~kg} \mathrm{ha}^{-1}$ ), além de duas testemunhas, uma capinada e outra mantida infestada. As cultivares de soja influenciaram na infestação das espécies de plantas daninhas na área. Sem a aplicação de glyphosate, houve o predomínio de X. strumarium na área, desfavorecendo a ocorrência de outras espécies. Quando utilizado glyphosate, independentemente da dose, a infestação contabilizada aos 35 e 40 dias após a primeira aplicação, no primeiro e segundo ano, respectivamente, foi baixa. O controle de plantas daninhas na cultura da soja transgênica é diretamente influenciado pela dose de glyphosate, havendo controle satisfatório com a aplicação única de $0,96 \mathrm{~kg} \mathrm{ha}^{-1}$ ou a sequencial de $0,48+0,48 \mathrm{~kg} \mathrm{ha}^{-1}$ de glyphosate. Em situação de menor infestação (2006/ 2007), a aplicação única de $0,48 \mathrm{~kg} \mathrm{ha}^{-1}$ de glyphosate é suficiente para o controle das plantas daninhas. As cultivares de soja transgênica CD 214 RR e M-SOY 8008 RR influenciam diferencialmente a dinâmica das espécies de plantas daninhas, sendo o controle químico mais efetivo na situação de cultivo de M-SOY 8008 RR, em que houve menor diversidade e desenvolvimento das plantas daninhas.
\end{abstract}

Palavras-chave: controle químico, soja transgênica, Xanthium strumarium.

\section{ABSTRACT \\ WEED CONTROL IN GLYPHOSATE TOLERANT SOYBEAN CROP}

This work evaluated the weed control in glyphosate tolerant soybean crop without additional management practices. Two experiments were carried out under field conditions in the agricultural years 2006/2007 and 2007/2008 in Jaboticabal, São Paulo State, Brazil. It was tested two glyphosate-tolerant varieties (CD 214 RR and M-SOY 8008 RR), eight herbicide treatments (Roundup Ready, single spraying at rates of $0.48 ; 0.72 ; 0.96$ and $1.20 \mathrm{~kg} \mathrm{ha}^{-1}$ of glyphosate acid equivalent, associates or not to sequential spraying at $0.48 \mathrm{~kg} \mathrm{ha}^{-1}$ ), and two controls (one under mechanical control and one untreated control). Soybean varieties influenced the infestation of weed species. Xanthium strumarium was predominant in control treatments, reducing the occurrence of other weeds species. Independently of the dose, glyphosate sprayings resulted in low infestations 35 and 40 days after the first spraying, in the first and second year, respectively. The weed control in transgenic soybean is directly influenced for the glyphosate rate, having satisfactory control with the single application at $0.96 \mathrm{~kg} \mathrm{ha}^{-1}$ or sequential at 0.48 plus $0.48 \mathrm{~kg}$ $\mathrm{ha}^{-1}$ of glyphosate. Under lesser infestation conditions $(2006 / 2007)$, the single application at $0.48 \mathrm{~kg} \mathrm{ha}^{-1}$ of glyphosate is enough for weed control. The varieties of transgenic soybean CD 214 RR and M-SOY 8008 RR distinguishing influence the dynamics of the weed species. The chemical control is more effective in the M-SOY 8008 RR, where it had minor diversity and development of the weed.

Key words: Chemical control, transgenic soybean, Xanthium strumarium.

( $\left.{ }^{1}\right)$ Recebido para publicação em 21 de maio de 2008 e aceito em 9 de dezembro de 2009.

$\left({ }^{2}\right)$ Departamento de Fitossanidade, Universidade Estadual Paulista (UNESP), Via de Acesso Prof. Paulo Donato Castellane, s/n. ${ }^{\circ}$, Jaboticabal (SP) Brasil. E-mail: correianm@fcav.unesp.br $\left(^{*}\right)$ Autora correspondente. 


\section{INTRODUÇÃO}

Alguns questionamentos ainda são feitos sobre o uso de plantas geneticamente modificadas, dentre eles o grau de tolerância de algumas plantas daninhas ao glyphosate, a interação com a simbiose de microrganismos com as raízes da soja e patógenos de plantas, os efeitos sobre a produção e a interação com as condições ambientais (PLINE-SNiRC, 2005). Grande parte desses fatores também é influenciada pelo manejo da cultura, dificultando isolar os efeitos do glyphosate.

O glyphosate possui amplo espectro de controle de plantas daninhas, porém, o uso exclusivo desse herbicida em áreas de soja transgênica pode ter limitações. Algumas espécies podem requerer doses mais elevadas de glyphosate, o emprego de aplicação sequencial, ou ainda a adição de outro herbicida para controle adequado (AtEH e HARVEY, 1999). Entre as espécies tolerantes pode-se citar Commelina benghalensis (Lacerda e Victoria Filho, 2004; Monquero et al., 2005), Richardia brasiliensis (MONQUERO et al., 2005), espécies do gênero Ipomoea (Norris et al., 2001), Sesbania exaltata e Sida spinosa (LANIE et al., 1994).

Diversos trabalhos foram realizados para avaliar o sistema de produção de soja transgênica e o controle de plantas daninhas. ReDDy (2003) relatou que a matéria seca de Echinochloa crus-galli, Brachiaria ramosa, Ipomoea lacunosa, Sesbania exaltata, Sida spinosa, Senna obtusifolia e Amaranthus hybridus foi menor sob cultivo de soja transgênica, em aplicação única e sequencial de glyphosate, do que na soja convencional, pulverizada com acifluorfen mais bentazon mais clethodim e com a associação dessa mistura à aplicação sequencial de chlorimuron. Mesmo com diferenças na porcentagem de controle das plantas daninhas, os sistemas convencional e transgênico resultaram em produção similar de grãos.

O glyphosate, em aplicação única ou sequencial, foi altamente eficaz no controle de Sorghum halepense em soja transgênica (GRIFFIN et al., 2006). A aplicação única ocorreu aos 30 dias após a semeadura, quando a gramínea estava com $40 \mathrm{~cm}$ de altura, nas doses de 0,$84 ; 1,12$ e $2,24 \mathrm{~kg} \mathrm{ha}^{-1}$ de glyphosate. Na aplicação sequencial (aos 30 e 60 dias após a semeadura) as plantas estavam com 39 e 90 $\mathrm{cm}$ de altura respectivamente. A aplicação isolada de quizalofop, fluazifop ou clethodim resultou em controle médio de $90 \%$.

Mesmo sabendo que as mudanças na comunidade infestante podem ser agravadas pela presença de espécies de difícil controle, o agricultor não deixará de utilizar a tecnologia enquanto verificar vantagens financeiras e, principalmente, operacionais
(GAZZIERO, 2006). No entanto, não há dúvidas que existe risco de seleção de espécies indesejáveis com o aumento de aplicações de glyphosate. Nos Estados Unidos da América do Norte, segundo levantamento feito por doze pesquisadores, houve aumento na infestação de Ipomoea sp. e Commelina sp. nos campos de produção de soja transgênica e de plantas daninhas anuais de inverno com tolerância natural ao glyphosate (CULPEPPER, 2006).

A hipótese do estudo é que o controle de plantas daninhas na cultura da soja transgênica é diretamente influenciado pela dose de glyphosate e variável em função da cultivar utilizada e da diversidade de populações da comunidade infestante da área. Portanto, o objetivo do presente trabalho foi avaliar o controle de plantas daninhas com o herbicida glyphosate em uma área com duas cultivares de soja resistente a este herbicida, sem práticas complementares de manejo de plantas daninhas, em dois anos agrícolas consecutivos.

\section{MATERIAL E MÉTODOS}

Foi desenvolvido experimento, em condições de campo, nos anos agrícolas 2005/2006 e 2006/2007, em Jaboticabal (SP). Nos dois anos, os experimentos foram instalados na mesma área experimental, seguindo-se a mesma disposição das parcelas.

O delineamento experimental utilizado foi o de blocos ao acaso, em esquema de parcelas subdivididas, com quatro repetições. Foram avaliadas nas parcelas duas cultivares de soja resistente ao glyphosate (CD 214 RR e M-SOY 8008 RR) e nas subparcelas oito tratamentos de herbicidas (glyphosate, em aplicação única, nas doses de 0,48; 0,$72 ; 0,96$ e $1,20 \mathrm{~kg} \mathrm{ha}^{-1}$ de equivalente ácido, associadas ou não a aplicação sequencial na dose de $0,48 \mathrm{~kg} \mathrm{ha}^{-1}$ ), além de duas testemunhas, uma mantida infestada e outra capinada, até a formação do dossel das plantas de soja.

Quinze dias antes e também no dia da semeadura, foi realizada a dessecação das plantas daninhas presentes na área experimental utilizandose $1,44 \mathrm{~kg} \mathrm{ha}^{-1}$ de equivalente ácido de glyphosate, na primeira aplicação, e $0,72 \mathrm{~kg} \mathrm{ha}^{-1}$, na segunda.

Com base na análise do solo, um Latossolo Vermelho-Escuro eutrófico típico de textura argilosa, e na necessidade nutricional da cultura, foi feita a adubação que consistiu da aplicação de $300 \mathrm{~kg} \mathrm{ha}^{-1}$ de 04-30-15 no sulco de semeadura, no primeiro ano, e $320 \mathrm{~kg} \mathrm{ha}^{-1}$ de 00-20-20, no segundo. Nos dois anos agrícolas, no sulco de semeadura também foi aplicado inoculante líquido [composição: Bradyrhizobium japonicum (estirpes Semia 5079 e Semia 5080], na quantidade de $3 \mathrm{~mL} \mathrm{~kg}^{-1}$ de sementes de soja. 
A soja foi semeada no sistema de plantio direto, a uma profundidade de $5 \mathrm{~cm}$, com $45 \mathrm{~cm}$ de distância entre linhas e 25 sementes por metro. No ano seguinte, foram colocadas 20 sementes por metro.

As parcelas (cultivares de soja) tinham 3,15 $\mathrm{m}$ de largura e $45 \mathrm{~m}$ de comprimento e as subparcelas (doses de glyphosate e testemunhas), 3,15 m de largura e $5 \mathrm{~m}$ de comprimento (sete linhas de $5 \mathrm{~m}$ de comprimento).

A primeira aplicação de glyphosate foi realizada aos 24 dias após a semeadura, no primeiro ano, e aos 23 , no segundo, quando as plantas de soja estavam com o terceiro trifólio totalmente expandido e as plantas daninhas com 4 a 6 folhas definitivas (para as dicotiledôneas) ou 2 perfilhos (para as gramíneas). Nos tratamentos indicados, a aplicação sequencial foi realizada 11 dias após a primeira, em 2005/2006, e 8 dias, no ano seguinte.

O herbicida, nas diferentes doses, foi aplicado com auxílio de pulverizador costal, à pressão constante mantida por $\mathrm{CO}_{2}$ comprimido de $2,9 \mathrm{kgf} \mathrm{cm}^{-2}$, munido de barra com seis bicos de jato plano (leque) XR11002, espaçados de $0,5 \mathrm{~m}$, com consumo de calda equivalente a $200 \mathrm{~L} \mathrm{ha}^{-1}$. No momento das pulverizações, foram registrados os valores da temperatura do ar, temperatura do solo (a $5 \mathrm{~cm}$ de produndidade), umidade relativa do ar e velocidade do vento (Tabela 1).

Aos 5, 10 e 15 dias após a primeira aplicação (DAPA) dos herbicidas, em 2005/2006, e aos 4, 12, 18 e 25 DAPA, no ano seguinte, foram realizadas avaliações visuais de controle das plantas daninhas, atribuindo-se notas em porcentagem, em que zero representa a ausência de injúrias visuais e 100 a morte da planta.

Aos 35 dias após a primeira aplicação (DAA) do herbicida, em 2005/2006, e aos 40 dias, no ano seguinte, foi feita a contagem do número de plantas daninhas (por espécie) em uma área de $0,45 \mathrm{~m}^{2}$, escolhida aleatoriamente dentro da área útil da subparcela. As plantas daninhas tiveram a parte aérea coletada e seca em estufa a $50{ }^{\circ} \mathrm{C}$ até massa constante.

No fim do ciclo da cultura, foi quantificada a produção de grãos de soja. Manualmente no primeiro ano e com auxílio de colhedora experimental em 2006/2007 foram colhidas três linhas com $4 \mathrm{~m}$ de comprimento, sendo posteriormente trilhadas e a produção corrigida para $13,0 \%$ de umidade.

Os resultados foram submetidos ao teste $\mathrm{F}$ da análise de variância. Os efeitos das cultivares, das doses de glyphosate e suas interações, quando significativos, foram comparados pelo teste de Tukey a $5 \%$ de probabilidade. Para as avaliações visuais de controle, as notas foram estabelecidas em função das parcelas testemunhas e não houve a inclusão deste tratamento na análise estatística, obtendo-se, assim, melhor distribuição e homogeneidade das notas de controle, não sendo necessária a transformação dos dados.

Os dados referentes à infestação (contagem e matéria seca de plantas) não foram submetidos à análise estatística, sendo as médias analisadas por meio de frequência e gráficos.

\section{RESULTADOS E DISCUSSÃO}

A interação cultivares e doses de glyphosate foi significativa apenas para a avaliação visual de controle aos 12 dias após a primeira aplicação (DAPA) do herbicida em 2006/ 2007, mostrando comportamento diferenciado e dependente entre os fatores. Nas outras épocas de avaliação e em ambos os anos de estudo, a porcentagem de controle foi influenciada unicamente pelo herbicida. O mesmo comportamento foi observado para produtividade de grãos de soja. Em 2005/2006 houve diferença significativa entre as cultivares para produção de grãos.

Tabela 1. Temperaturas do ar e do solo, umidade relativa do ar e velocidade do vento registrados no momento das aplicações de glyphosate. Jaboticabal (SP), 2006/2007

\begin{tabular}{|c|c|c|c|c|c|}
\hline \multirow{2}{*}{ Ano agrícola } & \multirow{2}{*}{ Aplicação } & \multicolumn{2}{|c|}{ Temperatura } & \multirow{2}{*}{ Umidade relativa do ar } & \multirow{2}{*}{ Velocidade do vento } \\
\hline & & $\mathrm{Ar}$ & Solo & & \\
\hline & & 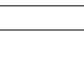 & +2 & $\%$ & $\mathrm{~km} \mathrm{~h}^{-1}$ \\
\hline \multirow[t]{2}{*}{$2005 / 2006$} & Primeira & 29,3 & 26,9 & 83,0 & 4,0 \\
\hline & Sequencial & 27,0 & 26,7 & 77,0 & 3,0 \\
\hline \multirow[t]{2}{*}{$2006 / 2007$} & Primeira & 31,7 & 28,7 & 70,0 & 3,0 \\
\hline & Sequencial & 29,1 & 27,6 & 88,0 & 3,3 \\
\hline
\end{tabular}


No primeiro ano do estudo, aos 5 e 10 DAPA (Tabela 2) os melhores resultados de controle das plantas daninhas foram obtidos com as maiores doses de glyphosate $\left(0,72 ; 0,96\right.$ e $\left.1,20 \mathrm{~kg} \mathrm{ha}^{-1}\right)$. Aos 15 DAPA (Tabela 3) a aplicação sequencial às doses de $0,48 \mathrm{e}$ $1,20 \mathrm{~kg} \mathrm{ha}^{-1}$ contribuiu para o controle das plantas daninhas, comparado à aplicação única dessas doses. O mesmo não foi observado quando pulverizado 0,72 e $0,96 \mathrm{~kg} \mathrm{ha}^{-1}$ de glyphosate. A aplicação única de 0,96 $\mathrm{kg} \mathrm{ha}^{-1}$ ou a sequencial de 0,48 mais $0,48 \mathrm{~kg} \mathrm{ha}^{-1}$ foram suficientes para o controle satisfatório das plantas daninhas.

Tabela 2. Porcentagem de controle de plantas daninhas aos 5 e 10 dias após a primeira aplicação de glyphosate, realizada 11 dias após a primeira, além da testemunha mantida infestada, sem a aplicação de herbicida. Jaboticabal (SP), 2005/2006

\begin{tabular}{llc}
\hline \multirow{2}{*}{ Glyphosate } & \multicolumn{2}{c}{ Dias após a primeira aplicação } \\
\cline { 2 - 3 } kg ha $^{-1}$ & 5 & 10 \\
\cline { 2 - 3 } 0,48 & $84,69 \mathrm{c}$ & $93,31 \mathrm{~b}$ \\
0,72 & $91,62 \mathrm{~b}$ & $96,62 \mathrm{a}$ \\
0,96 & $97,19 \mathrm{a}$ & $97,56 \mathrm{a}$ \\
1,20 & $97,94 \mathrm{a}$ & $97,81 \mathrm{a}$ \\
\hline Testemunha & 0,00 & 0,00 \\
infestada $\left({ }^{1}\right)$ & & 2,75 \\
\hline DMS & 5,04 &
\end{tabular}

Médias seguidas da mesma letra, na coluna, não diferem significativamente entre si pelo teste de Tukey a $5 \%$ de probabilidade. ${ }^{1}$ ) Os dados da testemunha infestada não foram incluídos na análise estatística.

Em 2005/2006, a produtividade de grãos de soja (Tabela 3) na testemunha mantida infestada foi estatisticamente igual ao tratamento com 0,48 $\mathrm{kg} \mathrm{ha}^{-1}$ (aplicação única) e 0,48 mais $0,48 \mathrm{~kg} \mathrm{ha}^{-1}$ (aplicação sequencial), os quais não diferiram dos outros tratamentos. A cultivar CD 214 RR $(3567,10$ $\mathrm{kg} \mathrm{ha}^{-1}$ ) foi mais produtiva do que a M-SOY 8008 RR $\left(2247,25 \mathrm{~kg} \mathrm{ha}^{-1}\right)$, sendo de $37 \%$ a diferença entre elas.

A densidade da principal planta daninha da área experimental, $X$. strumarium, era em média de 16 plantas $\mathrm{m}^{-2}$ nas testemunhas infestadas, ocasionando perdas de $27 \%$ na produção de grãos de soja, em relação às testemunhas capinadas (Tabela 3). No momento da colheita, as plantas daquela espécie estavam, em média, com 1,60 m de altura e caule rígido, bem lignificado, o que dificultaria a colheita mecanizada dos grãos de soja. Como no experimento as plantas de $X$. strumarium foram cortadas e a soja colhida manualmente em 2005/2006, não houve prejuízos na colheita. Em condições similares de campo, além dos danos causados no potencial produtivo da cultura, outro grande prejuízo dessa planta daninha é a interferência na colheita, resultando também em perdas no rendimento da colhedora e na qualidade do produto colhido.

Em 2006/2007, aos 4 DAPA os tratamentos herbicidas não diferiram entre si. Na avaliação feita aos 12 DAPA (Tabela 4) os efeitos dos tratamentos herbicidas foram dependentes da cultivar de soja estudada. Para a CD 214 RR, as maiores porcentagens de controle ocorreram com a primeira aplicação de glyphosate $\left(0,48 ; 0,72 ; 0,96\right.$ e $\left.1,20 \mathrm{~kg} \mathrm{ha}^{-1}\right)$, seguida da sequencial. No entanto, para a M-SOY 8008 RR, não houve diferença entre os tratamentos herbicidas testados. Comparando as duas cultivares, houve diferença significativa entre elas apenas para as aplicações únicas de 0,$48 ; 0,72$ e $1,20 \mathrm{~kg} \mathrm{ha}^{-1}$ de glyphosate, com maior eficácia nas parcelas com MSOY 8008 RR.

Com o passar do tempo, não foram constatadas diferenças significativas entre as cultivares. Nas avaliações visuais realizadas aos 18 e 25 DAPA (Tabela 5), a aplicação sequencial contribuiu para o controle das plantas daninhas apenas quando associada a $1,20 \mathrm{~kg} \mathrm{ha}^{-1}$ de glyphosate, comparado às aplicações únicas. De forma geral, todos os tratamentos herbicidas foram eficazes no controle das plantas daninhas, refletindo-se diretamente na produtividade de grãos de soja (Tabela 5). Os tratamentos herbicidas diferiram somente da testemunha mantida infestada. A população de $X$. strumarium nas testemunhas infestadas era de 36 plantas por $\mathrm{m}^{2}$, resultando em decréscimo de $65 \%$ na produção de grãos de soja, em relação à testemunha capinada.

No segundo ano do estudo, não houve diferença significativa entre as cultivares para produção de grãos, o que pode ser explicado pelo melhor arranjo espacial das plantas da M-SOY 8008 RR em 2006/2007. Ao invés de 20 plantas por metro linear, obteve-se 16, promovendo-se melhor arquitetura das plantas devido ao seu menor porte e maior ramificação. Em função da maior altura das plantas em 2005/2006, associado à facilidade de acamamento das plantas dessa cultivar, no início do enchimento de grãos as plantas acamaram, interferindo diretamente nos resultados de produção desse ano agrícola. 
Tabela 3. Produtividade de grãos de soja transgênica e porcentagem de controle de plantas daninhas aos 15 dias após a primeira aplicação (DAPA) de glyphosate, associado ou não a sua aplicação sequencial, realizada 11 dias após a primeira, além das testemunhas sem a aplicação de herbicidas, uma mantida infestada e outra capinada. Jaboticabal (SP), 2005/2006

\begin{tabular}{|c|c|c|c|}
\hline \multicolumn{2}{|c|}{ Aplicações de glyphosate } & \multirow{2}{*}{ Controle 15 DAPA } & \multirow{2}{*}{ Produção de grãos } \\
\hline Primeira & Sequencial & & \\
\hline \multicolumn{2}{|c|}{$\mathrm{kg} \mathrm{ha}^{-1}$} & $\%$ & $\mathrm{~kg} \mathrm{ha}^{-1}$ \\
\hline \multirow[t]{2}{*}{0,48} & 0 & $91,12 \mathrm{~d}$ & $2853,46 \mathrm{ab}$ \\
\hline & 0,48 & $98,00 \mathrm{ab}$ & $2780,41 \mathrm{ab}$ \\
\hline \multirow[t]{2}{*}{0,72} & 0 & $94,50 \mathrm{bcd}$ & $3035,86 \mathrm{a}$ \\
\hline & 0,48 & $97,88 \mathrm{abc}$ & $2982,42 \mathrm{a}$ \\
\hline \multirow[t]{2}{*}{0,96} & 0 & $96,50 \mathrm{abc}$ & 3050,06 a \\
\hline & 0,48 & $98,00 \mathrm{ab}$ & 2985,13 a \\
\hline \multirow[t]{2}{*}{1,20} & 0 & $93,88 \mathrm{~cd}$ & 3064,49 a \\
\hline & 0,48 & 99,00 a & 3004,97 a \\
\hline \multicolumn{2}{|c|}{ Testemunha infestada $\left({ }^{1}\right)$} & 0,00 & $2233,44 \mathrm{~b}$ \\
\hline \multicolumn{2}{|c|}{ Testemunha capinada } & 3081,63 a & \\
\hline \multicolumn{2}{|l|}{ DMS } & 4,03 & 671,32 \\
\hline
\end{tabular}

Médias seguidas da mesma letra, na coluna, não diferem significativamente entre si pelo teste de Tukey a $5 \%$ de probabilidade.

${ }^{1}$ ) Os dados da testemunha infestada não foram incluídos na análise estatística.

Tabela 4. Porcentagem de controle de plantas daninhas nas parcelas de duas cultivares de soja transgênica (CD 214 RR e M-SOY 8008 RR), aos 12 dias após a primeira aplicação de glyphosate, associado ou não a sua aplicação sequencial, realizada 8 dias após a primeira, além da testemunha mantida infestada, sem a aplicação de herbicida. Jaboticabal (SP), 2006/2007

\begin{tabular}{|c|c|c|c|}
\hline \multicolumn{2}{|c|}{ Aplicações de glyphosate } & \multicolumn{2}{|c|}{ Cultivares de soja } \\
\hline Primeira & Sequencial & CD 214 RR & M-SOY 8008 RR \\
\hline \multicolumn{2}{|l|}{$\mathrm{kg} \mathrm{ha}^{-1}$} & 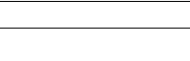 & 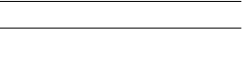 \\
\hline \multirow[t]{2}{*}{0,48} & 0 & 83,75 b B & $93,75 \mathrm{~A}$ \\
\hline & 0,48 & 96,50 a $\mathrm{A}$ & $94,50 \mathrm{~A}$ \\
\hline \multirow[t]{2}{*}{0,72} & 0 & 85,50 b B & $93,75 \mathrm{~A}$ \\
\hline & 0,48 & 95,00 a $\mathrm{A}$ & $94,75 \mathrm{~A}$ \\
\hline \multirow[t]{2}{*}{0,96} & 0 & $90,00 \mathrm{ab} \mathrm{A}$ & $94,50 \mathrm{~A}$ \\
\hline & 0,48 & 94,25 a A & $96,25 \mathrm{~A}$ \\
\hline \multirow[t]{2}{*}{1,20} & 0 & $89,50 \mathrm{ab} \mathrm{A}$ & $94,50 \mathrm{~A}$ \\
\hline & 0,48 & 96,50 a $\mathrm{A}$ & $98,25 \mathrm{~A}$ \\
\hline Testemunha infestada $\left({ }^{1}\right)$ & - & 0,00 & 0,00 \\
\hline d.m.s (na linha) & & & \\
\hline DMS (na coluna) & & & \\
\hline
\end{tabular}

Com base no teste de Tukey a 5\% de probabilidade, médias seguidas de letra minúscula, nas colunas, comparam os tratamentos herbicidas dentro de cada cultivar de soja e, letras maiúsculas, nas linhas, comparam as duas cultivares para cada tratamento herbicida.

$\left({ }^{1}\right)$ Os dados da testemunha infestada não foram incluídos na análise estatística. 
Tabela 5. Produtividade de grãos de soja transgênica e porcentagem de controle de plantas daninhas aos 18 e 25 dias após a primeira aplicação (DAPA) de glyphosate, associado ou não a sua aplicação sequencial, realizada 8 dias após a primeira, além das testemunhas sem a aplicação de herbicidas, uma mantida infestada e outra capinada. Jaboticabal (SP), 2006/2007

\begin{tabular}{|c|c|c|c|c|}
\hline \multicolumn{2}{|c|}{ Aplicações de glyphosate } & \multicolumn{2}{|c|}{ Dias após a primeira aplicação } & \multirow{2}{*}{ Produção de grãos } \\
\hline Primeira & Sequencial & 18 & 25 & \\
\hline \multicolumn{2}{|c|}{$\mathrm{kg} \mathrm{ha}^{-1}$} & \multicolumn{2}{|c|}{$\%$} & $\mathrm{~kg} \mathrm{ha}^{-1}$ \\
\hline \multirow{2}{*}{0,48} & 0 & 88,00 bc & $88,88 \mathrm{ab}$ & 2944,58 a \\
\hline & 0,48 & $94,25 \mathrm{ab}$ & $93,00 \mathrm{ab}$ & 3147,12 a \\
\hline \multirow[t]{2}{*}{0,72} & 0 & $86,00 \mathrm{c}$ & $88,00 \mathrm{~b}$ & 3207,82 a \\
\hline & 0,48 & $91,00 \mathrm{abc}$ & $92,12 \mathrm{ab}$ & 3097,47 a \\
\hline \multirow[t]{2}{*}{0,96} & 0 & 89,12 abc & $91,62 \mathrm{ab}$ & 3109,38 a \\
\hline & 0,48 & $91,37 \mathrm{abc}$ & $92,50 \mathrm{ab}$ & 3056,99 a \\
\hline \multirow[t]{2}{*}{1,20} & 0 & $87,75 \mathrm{bc}$ & $87,75 \mathrm{~b}$ & 3150,73 a \\
\hline & 0,48 & 95,25 a & 94,38 a & 3097,80 a \\
\hline Testemunha infestada $\left({ }^{1}\right)$ & - & 0,00 & 0,00 & $1157,46 \mathrm{~b}$ \\
\hline Testemunha capinada & - & - & - & 3343,80 a \\
\hline DMS & - & 6,55 & 6,25 & 852,47 \\
\hline
\end{tabular}

Médias seguidas da mesma letra não diferem significativamente entre si pelo teste de Tukey a $5 \%$ de probabilidade.

${ }^{(1)}$ Os dados da testemunha infestada não foram incluídos na análise estatística.

A menor variabilidade de controle das plantas daninhas no segundo ano, principalmente, quando utilizado $0,48 \mathrm{~kg} \mathrm{ha}^{-1}$ de glyphosate, pode ser explicada pela ação do glyphosate no manejo das plantas daninhas no ano anterior. Houve diminuição do potencial de infestação da área, em virtude da menor produção de sementes e, consequentemente, menor deposição ao solo. O controle em 2005/2006 foi fundamental para maior eficácia do herbicida no ano seguinte. Na área experimental, constatou-se maior fluxo de germinação de sementes de $X$. strumarium produzidas no ano anterior, localizadas mais na superfície do solo.

Quanto às avaliações de infestação (contagem e matéria seca de plantas), no primeiro ano do estudo, a comunidade infestante foi composta por quatro espécies dicotiledôneas: Acanthospermum hispidum, Portulaca oleracea, Senna obtusifolia e Xanthium strumarium, e quatro monocotiledôneas: Commelina benghalensis, Cenchrus echinatus, Digitaria sp. e Eleusine indica. No ano seguinte, não foi constatada a ocorrência de $P$. oleracea e, além das outras espécies de dicotiledôneas mencionadas anteriormente, houve infestação de Alternanthera tenella e Richardia brasiliensis. A espécie predominante na área experimental foi X. strumarium.
Nas parcelas com a cultivar CD 214 RR, o número de plantas daninhas emergidas foi maior no segundo ano do que no primeiro (Figura 1), enquanto para a M-SOY 8008 RR a emergência foi menor em 2006/2007, independentemente da dose de glyphosate aplicada. O mesmo ocorreu para matéria seca de plantas daninhas. Esse efeito pode ser justificado pelo rápido crescimento inicial e estabelecimento das plantas dessa cultivar, permitindo o rápido fechamento do dossel das plantas e, consequentemente, sombreamento precoce da área, contribuindo com o controle químico. As duas cultivares estudadas possuem ciclo médio em torno de 120 dias e ambas são recomendadas para o Estado de São Paulo.

Norsworthy e Oliveira (2007a) constataram efeito do fechamento do dossel das plantas de soja na emergência de $X$. strumarium. No primeiro ano do estudo, a redução da emergência de $X$. strumarium foi de $50 \%$, comparado às parcelas sem soja, e iniciou-se no estádio $V_{5}$ da soja, quando a interceptação da luz pelas plantas foi de $30 \%$ (Norsworthy e Oliveira, 2007a). No segundo ano, o mesmo ocorreu a partir do estádio $\mathrm{V}_{6}$, com $75 \%$ de interceptação da luz pelas plantas de soja, e decréscimo de $44 \%$ na emergência da planta 
daninha. A luz não é o fator de maior importância na germinação de $X$. strumarium e, sim, a temperatura do solo, especialmente as condições de grande amplitude térmica diária (NORSWORTHY e Oliveira, 2007a), o que é desfavorecido a partir do sombreamento do terreno pelo dossel das plantas. Estratégias que antecipem o fechamento do dossel da cultura podem contribuir para redução na emergência de $X$. strumarium (Norsworthy e Oliveira, 2007b).
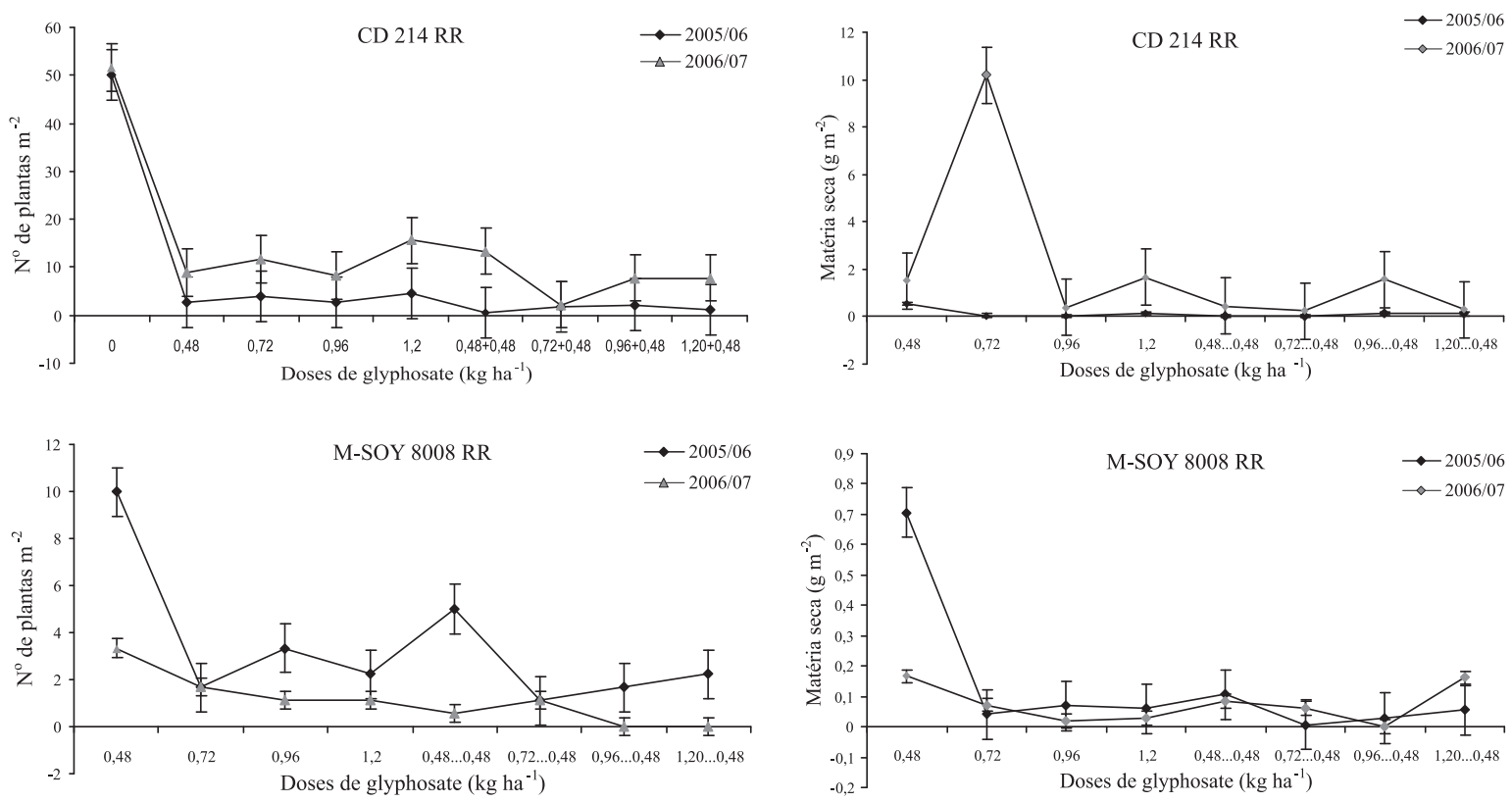

Figura 1. Número de plantas e matéria seca $\left(\mathrm{g} \mathrm{m}^{-2}\right)$ da parte aérea de plantas daninhas em convivência com duas cultivares de soja transgênica (CD 214 RR e M-SOY 8008 RR), aos 35 dias após a primeira aplicação de glyphosate, em 2005/2006, e aos 40 dias, em 2006/2007. As barras verticais representam o desvio-padrão da média. Jaboticabal (SP), 2005/2006 e 2006/2007.

Para as duas cultivares, nos tratamentos sem aplicação de herbicida (testemunhas mantidas infestadas), a matéria seca das plantas daninhas foi em torno de cinco vezes maior no segundo ano em relação ao primeiro, com valores médios de 147,45 $\mathrm{g} \mathrm{m}^{-2} \mathrm{em} \mathrm{2005/2006} \mathrm{e}$ $803,24 \mathrm{~g} \mathrm{~m}^{-2}$ em 2006/2007. Nesses tratamentos, embora o número de plantas emergidas tenha sido quase o mesmo nos dois anos (média de 44,62 plantas $\mathrm{m}^{-2}$ ), a capacidade de acúmulo de massa das plantas em 2006/2007 aumentou exponencialmente.

De forma geral, nos dois anos do trabalho, com a aplicação sequencial de $0,48 \mathrm{~kg} \mathrm{ha}^{-1}$ de glyphosate houve menor número de plantas daninhas emergidas. Porém, não houve efeito consistente da aplicação sequencial na produção de massa pelas plantas, ou seja, a redução de matéria seca observada estava mais em função da dose de glyphosate utilizada na primeira aplicação do que na realização da aplicação sequencial.

Para a cultivar CD 214 RR, nas parcelas onde foi aplicado glyphosate (Figura 2), constatou-se, no segundo ano, aumentos não muito expressivos na matéria seca de A. hispidum, C. echinatus, Digitaria sp. e E. indica, além de acréscimos consideráveis de $X$. strumarium e a ocorrência de C. benghalensis e $R$. brasiliensis, não constatadas no ano anterior. No entanto, os valores obtidos foram inferiores a $41 \mathrm{mg}$ $\mathrm{m}^{-2}$ para $R$. brasiliensis, $800 \mathrm{mg} \mathrm{m}^{-2}$ para C. benghalensis e $1.000 \mathrm{mg} \mathrm{m}^{-2}$ para X. strumarium.

As plantas daninhas avaliadas não foram eliminadas pelo tratamento com glyphosate, sendo consideradas "escapes". As razões ecológicas para justificar os "escapes" de plantas daninhas a aplicações de glyphosate são diversas, como a proteção das plantas daninhas pelo dossel da cultura (efeito guarda-chuva), impedindo que o herbicida atinja o alvo; tolerância diferencial em função do estádio de desenvolvimento da planta daninha; condições ambientais; tecnologia de aplicação; tolerância individual; danos ocasionados por insetos, que dificultam a translocação do herbicida, etc (ScuRsoni et al., 2007).

Em 2006/2007, para a M-SOY 8008 RR houve redução no acúmulo de matéria seca de $A$. hispidum, C. echinatus, Digitaria sp. e X. strumarium e aumento no de $C$. benghalensis, quando comparado ao primeiro ano do trabalho. Também nesse ano, não se constatou infestação de $P$. oleracea. Nas parcelas com essa cultivar, nos dois anos do estudo, não foi identificada a emergência de R. brasiliensis. 

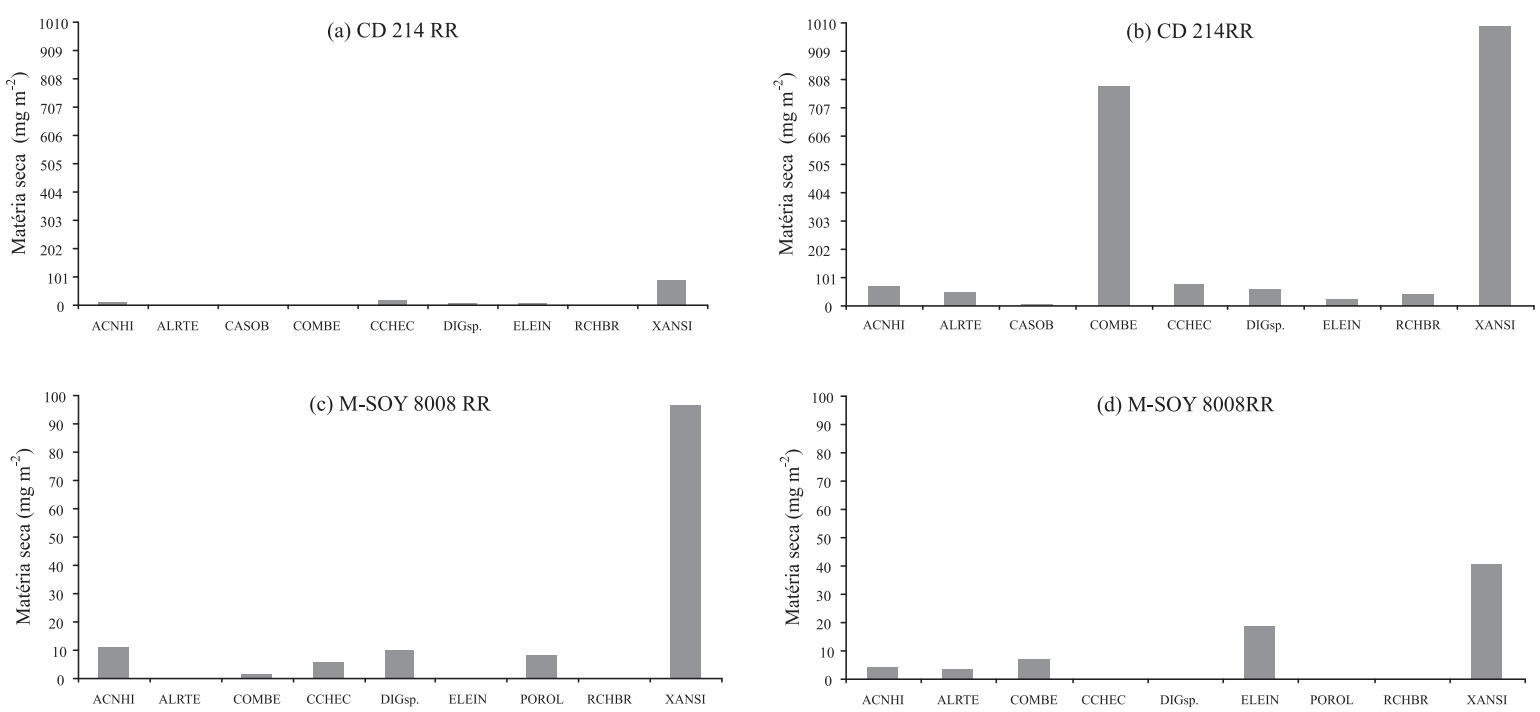

Figura 2. Matéria seca $\left(\mathrm{mg} \mathrm{m}^{-2}\right)$ da parte aérea de Acanthospermum hispidum (ACNHI), Alternanthera tenella (ALRTE), Senna obtusifolia (CASOB), Commelina benghalensis (COMBE), Cenchrus echinatus (CCHEC), Digitaria sp. (DIGsp.), Eleusine indica (ELEIN), Portulaca oleracea (POROL), Richardia brasiliensis (RCHBR) e Xanthium strumarium (XANSI) em convivência com duas cultivares de soja transgênica (CD 214 RR e M-SOY 8008 RR), aos 35 dias após a primeira aplicação de glyphosate, em 2005/2006 (a, c), e aos 40 dias, em 2006/2007 (b,d). Jaboticabal (SP), 2005/2006 e 2006/2007.

Nas testemunhas mantidas infestadas (sem a aplicação de glyphosate), as plantas de X. strumarium tiveram maior acúmulo de massa (dados não mostrados). Devido à alta infestação dessa espécie nesses tratamentos, outras plantas daninhas não conseguiram se estabelecer na área. Em 2006/2007, comparado ao ano anterior, ocorreram acréscimos de seis a oito vezes na matéria seca de $X$. strumarium, com médias próximas a $1.000 \mathrm{~g} \mathrm{~m}^{-2}$ e $525 \mathrm{~g} \mathrm{~m}^{-2}$, respectivamente, para as áreas com as cultivares $C D$ 214 RR e M-SOY 8008 RR.

Com a adoção do sistema de produção de soja transgênica, as espécies de plantas daninhas com maior probabilidade de aumentar sua frequência ao longo do tempo são aquelas com tolerância natural ao glyphosate ou são controladas apenas parcialmente pelo produto. Além disso, o uso contínuo de herbicidas com o mesmo mecanismo de ação pode aumentar a pressão de seleção de biótipos de plantas daninhas resistentes. Até 2009 foram relatadas 16 espécies com biótipos resistentes ao glyphosate, sendo elas: Amaranthus palmeri, A. rudis, Ambrosia artemisiifolia, A. trifida, Conyza canadensis, C. bonariensis, Digitaria insularis, Echinochloa colona, Eleusine indica, Euphorbia heterophylla, Lolium rigidum, L. multiflorum, Parthenium hysterophorus, Plantago lanceolata, Sorghum halepense e Urochloa panicoides (Heap, 2009). No Brasil, foram registrados biótipos resistentes de $C$. canadensis, $C$. bonariensis, $D$. insularis, E. heterophylla e L. multiflorum (HEAP, 2009).
Em dois anos de estudo, Hilgenfeld (2004) verificou que as espécies Chenopodium album, Helianthus annus, A. rudis, Solanun ptycanthum, I. hederaceae e S. bicolor foram controladas com eficácia através da aplicação única de glyphosate, aos 35 dias após a semeadura (DAS) da soja transgênica, e outra sequencial, aos 21 e 47 DAS. No segundo ano, houve aumento de $25 \%$ e $60 \%$ na emergência de I. hederaceae e $S$. bicolor, respectivamente, em relação ao primeiro ano, justificada, segundo o autor, pela emergência tardia das plantas e à tolerância dessas espécies ao glyphosate. Fatores como susceptibilidade ao glyphosate e periodicidade de emergência das plantas daninhas contribuem para a mudança de flora e o aumento da infestação de algumas espécies (Hilgenfeld, 2004).

Em outro trabalho desenvolvido por três anos, Edenfield et al. (2005) relataram que o glyphosate proporcionou controle de $97 \%$ de Cyperus rotundus, aos 80 dias após a semeadura da soja, e redução de $71 \%$ no número de tubérculos, no primeiro ano. No terceiro ano, o controle foi de $99 \%$ e o número de tubérculos decresceu $99 \%$. A aplicação foi realizada em plantas de 15 a $20 \mathrm{~cm}$ de altura, indicando que o controle de espécies problemáticas a outros herbicidas, porém, sensíveis ao glyphosate, como C. rotundus, será facilitado no sistema de soja geneticamente modificado. No entanto, apesar da facilidade, simplicidade e flexibilidade do controle das plantas daninhas na 
soja tolerante ao glyphosate, outras estratégias de manejo não podem ser excluídas. Pelo contrário, o sistema de soja transgênica deve ser usado como parte de sistemas integrados de manejo, fundamentados no conhecimento, bom senso e responsabilidade, para que essa tecnologia possa ser utilizada em longo prazo. Práticas como rotação e sucessão de culturas, plantio direto, rotação e/ou mistura de herbicidas com diferentes mecanismos de ação e, é claro, monitoramento da ocorrência da plantas daninhas, são essenciais para o sucesso e bom uso das culturas geneticamente modificadas.

\section{CONCLUSÕES}

1. O controle de plantas daninhas na cultura da soja transgênica é diretamente influenciado pela dose de glyphosate, havendo controle satisfatório com a aplicação única de $0,96 \mathrm{~kg} \mathrm{ha}^{-1}$ ou a sequencial de $0,48+0,48 \mathrm{~kg} \mathrm{ha}^{-1}$ de glyphosate. Em situação de menor infestação (2006/2007), a aplicação única de $0,48 \mathrm{~kg} \mathrm{ha}^{-1}$ de glyphosate é suficiente para o controle das plantas daninhas.

2. As cultivares de soja transgênica CD $214 \mathrm{RR}$ e M-SOY 8008 RR influenciam diferencialmente a dinâmica das espécies de plantas daninhas, sendo o controle químico mais efetivo na situação de cultivo de M-SOY 8008 RR, em que houve menor diversidade e desenvolvimento das plantas daninhas.

\section{REFERÊNCIAS}

ATEH, C.A.; HARVEY, R.G. Annual weed control by glyphosate in glyphosate-resistant soybean (Glycine max). Weed Technology, v.13, p.394-398, 1999.

CULPEPPER, A.S. Glyphosate induced weed shifts. Weed Technology, v.20, p.277-281, 2006.

EDENFIELD, M.W.; BRECKE, B.J.; COLVIN, D.L.; DUSKY, J.A.; SHILLING, D.G. Purple nutsedge (Cyperus rotundus) control with glyphosate in soybean and cotton. Weed Technology, v.19, p.947-953, 2005.

GAZZIERO, D.L.P. Soja transgênica: o que muda no manejo das plantas daninhas. In: CONGRESSO BRASILEIRO DE SOJA, 4., 2006, Londrina. Anais... Londrina: EMBRAPA Soja, 2006. p.143-146.

GRIFFIN, J.L.; MILLER, D.K.; SALASSI, M.E. Jonhsongrass (Sorghum halepense) control and economics of using glyphosate-resistant soybean in fallowed sugarcane fields. Weed Technology, v.20, p.980-985, 2006.

HEAP, I. The international survey of herbicide resistant weeds. Disponível em <http:/ / www.weedscience.org> Acesso em 23 de setembro de 2009 .
HILGENFELD, K.L.; MARTIN, A.R.; MORTENSEN, D.A.; MASON S.C. Weed management in a glyphosate resistant soybean system: Weed Species Shifts. Weed Technology, v.18, p.284-291, 2004.

LACERDA, A.L.S.; VICTORIA FILHO, R. Curvas dose-resposta em espécies de plantas daninhas com o uso do herbicida glyphosate. Bragantia, v.63, p.73-79, 2004.

LANIE, A.J.; GRIFFIN, J.L.; VIDRINE, P.L.; REYNOLDS, D.B. Weed control with nonselective herbicides in soybean (Glycine max) stale seedbed culture. Weed Technology, v.8, p.159-164, 1994.

MONQUERO, P.A.; CURY, J.C.; CHRISTOFFOLETI, P.J. Controle pelo glyphosate e caracterização geral da superfície foliar de Commelina benghalensis, Ipomoea hederifolia, Richardia brasiliensis e Galinsoga parviflora. Planta Daninha, v.23, p.123132, 2005.

NORRIS, J.L.; SHAW, D.S.; SNIPES, C.E. Weed control from herbicide combination with three formulations of glyphosate. Weed Technology, v.15, p.552-558, 2001.

NORSWORTHY, J.K.; OLIVEIRA, M.J. Tillage and soybean canopy effects on commom cocklebur (Xanthium strumarium) emergence. Weed Science, v.55, p.474-480, 2007a.

NORSWORTHY, J.K.; OLIVEIRA, M.J. Light and temperature requirements for commom cocklebur (Xanthium strumarium) germination during after-ripening under field conditions. Weed Science, v.55, p.227-234, 2007b.

PLINE-SNIRC, W. Technical perfomance of some commercial glyphosate-resistante crops. Pest Management Science, v.61, p.225-234, 2005.

REDDY, K.N. Impact of rye cover crop and herbicides on weeds, yield, and net return in narrow-row transgenic and conventional soybean (Glycine max). Weed Technology, v.17, p. 28-35, 2003.

SCURSONI, J.L.; FORCELLA, F.; GUNSOLUS, J. Weed escapes and delayed weed emergence in glyphosate-resistant soybean. Crop Protection, v.26, p.212-218, 2007. 